DOI: $10.17805 / z p u .2016 .3 .25$

\title{
Дискуссия вокруг подражания языку Шекспира в английской культуре в последней трети XVII - начале XVIII века
}

\author{
А. И. КУЗЬМИЧЕВ \\ (ИНСТИТУТ НАУЧНОЙ ИНФОРМАЦИИ ПО ОБЩЕСТВЕННЫМ НАУКАМ РАН, \\ Г. МОСКВА)
}

Вторая половина XVII в. в Англии - время доминирования французской литературной критической школы, которая в первую очередь видела в произведениях искусства образцы для подражания и воспитания новых поколений аристократов. Шекспир, изображавший на сцене убийства и другие злодеяния, и речи героев которого нередко не соответствовали их социальному статусу, плохо подходил на роль воспитателя. Вкус эпохи гораздо больше благоволил к творческому дуэту Фрэнсиса Бомонта и Джона Флетчера, уделявшему серьезное внимание связности сюжетов пьес и изображению правильных манер и поступков.

В это же время впервые актуализировалась проблема совершенствования языка. Ее вероятным катализатором стало сочинение Самюэля Сорбьера о путешествии в Англию(1664). Английские интеллектуалы видели два способа ее разрешения: отстаивание культурной самобытности с опорой на язык третьего сословия и подстройка своего культурного наследия под главенствующие нормы эпохи. Вначале был выбран второй путь, автор статьи иллюстрирует его на примере шекспировских пьес.

Однако в конечном счете возобладало представление о преимуществе языковой модели третьего сословия, отстаиваемое историком Лондонского королевского общества Томасом Спратом и первым английским литературным критиком Томасом Раймером. Последний в выработке своей точки зрения прямо опирался на язык шекспировских пьес. При этом в эпоху Реставрации их аргументация оказалась невостребованной, и лишь во второй половине XVIII в. последующие поколения интеллектуалов 
смогли утвердить эту модель в качестве основной, тем самым поставив Шекспира в центр новообразованного канона английского языка.

Ключевые слова: У. Шекспир; язык шекспировских текстов; история литературы; английская литература; XVII век; Джон Драйден; Томас Раймер; Томас Спрат; Самюэль Сорбьер

\section{ВВЕАЕНИЕ}

Rторая половина XVII в. в Англии - пик доминирования французской критичеВской школы, в первую очередь видящей в произведениях искусства образцы для подражания и воспитания новых поколений аристократов. Шекспир, чья популярность только начала возвращаться после периода забвения во времена Английской Республики (со 2 сентября 1642 г. и до ее конца в Республике действовал парламентский запрет на театральные постановки как противоречащие христианской морали), плохо подходил на роль воспитателя. Вкус эпохи гораздо больше благоволил к творческому дуэту Фрэнсиса Бомонта и Ажона Флетчера, уделявшему серьезное внимание связности сюжетов пьес и изображению правильных манер и поступков, чем Шекспиру, показывавшему на сцене убийства и другие злодеяния, и речи героев которого нередко не соответствовали их социальному статусу. Первый литературный критик Англии Томас Раймер (1643?-1713) в «Кратком обзоре трагедии» (Short View of Tragedy; 1693) писал: «В ржании лошади и вое мастифа во много раз больше смысла, больше жизненности и, не побоюсь этого сказать, больше человечности, чем в трагедиях Шекспира» (Rymer, 1956: 135; здесь и далее перевод наш. - $A$. K.).

Описанная ситуация, а именно выбор аристократической культуры, в первую очередь манер и языка, в качестве базиса для построения культуры национальной, типична для старой Европы. Здесь можно вспомнить дворянскую культуру России или аристократическую - Франции; в меньшей степени этот тезис распространяется на Германию с ее богатыми вольными городами «Священной Римской империи Германской нации» (СРИГН). Раскрывая тезис, добавим, что речь идет не о сословной принадлежности основных деятелей культуры, а о способе мироощущения и выражения реальности, об «обществе вкуса» и «аристократии духа» по Х.-Г. Гадамеру ${ }^{1}$.

Тем интереснее уникальный выбор английской культуры, которая почти без колебаний предпочла языку аристократов язык третьего сословия. Шекспир сыграл в этом огромную роль, впервые подмеченную все тем же Раймером, превозносившим драматурга за использование языка купцов и лавочников, как более живого и свободно инкорпорирующего новые языковые модели.

В эпоху Реставрации ${ }^{2}$ начинает формироваться филологическая критика современного типа. Вначале речь идет о предисловиях и послесловиях авторов к собственным текстам и небольших эссе (характерный пример - вступления, эпилоги и их защиты Ажона Арайдена), но ближе к концу века вызревает необходимость в профессиональной и беспристрастной оценке (как известно, фигура критика появляется лишь на последнем этапе развития книгопечатания).

Реставрационная критика характеризуется наличием двух основных и взаимосвязанных проблем: спора древних и новых и проблемы улучшения языка; на последней и ее связи с Шекспиром мы и остановимся. 
ОСНОВНАЯ ПРОБАЕМАТИКА АИТЕРАТУРНОЙ КРИТИКИ

\section{ЭПОХИ РЕСТАВРАЦИИ: ИСТОКИ И РЕШЕНИЯ НА ПРИМЕРЕ ПЬЕС ШЕКСПИРА}

Происхождение этих вопросов в английской культуре остается туманным, но, кажется, нам удалось найти вероятный катализатор актуализации данных проблем в Англии после Реставрации. Речь идет о книге французского подданного Самюэля Сорбьера (1615-1670) «Путешествие в Англию, содержащее множество наблюдений об учености, религии и других диковинках этого королевства» (Relation d'un voyage en Angleterre, Où sont toucbées plusieurs choses, qui regardent l' estat des Sciences, \& de la Religion, \& autres matières curieuses; 1664). Известный в свое время врач, один из корреспондентов Т. Гоббса и переводчик «Утопии» Т. Мора на французский язык (1643), он в 1663-1664 гг. посетил Англию с научным визитом, о чем написал соответствующую книгу, в которой осторожно подверг критике английскую еду, английские обычаи, английский язык и английский театр. И если по поводу еды, кажется, возражать никто не стал, то последние три пункта вызвали настоящую бурю гнева в тем которого был Сорбьер, и один из основателей Общества и его первый историк, Томас Спрат (1635-1715), ответил на сочинение Сорбьера своими сатирическими «Наблюдениями за путешествием месье Сорбьера в Англию» (Observations upon Monsieur de Sorbier's Voyage into England; 1665).

Необходимо напомнить контекст появления этих двух книг. Только-только произошла Реставрация: Карл II вернулся в Англию из Франции и привез с собой французские вкусы; только-только было основано Мондонское королевское общество (1660 г., устав утвержден в 1662 г.). Перед нами ситуация, когда «известный общественный деятель и посланец ведущей мировой культуры посетил с частной инспекцией географическую и культурную периферию, недавно облагороженную силами его страны». Значимо, что и Спрат, и другие недовольные книгой Сорбьера читали ее по-французски (английский перевод вышел только в 1709 г.), таким образом, они изначально находились в подчиненном, защитном положении, поскольку вынуждены были строить свою аргументацию на чужом языке и в русле логики чужой культуры, и сами осознавали это.

Аля Сорбьера английский язык несовершенен, хотя и не лишен варварского очарования. В своих негативных оценках он сдержан, как и подобает гостю: «Я понимаю, что в основе всего английского красноречия лежит лишь жалкий педантизм; проповеди с кафедры и кабацкая ругань ничем не отличаются друг от друга... Английские книги написаны в основном в одной и той же манере и содержат только лишь высокопарное пустозвонство о вещах, которые плохо сочетаются друг с другом, и их все же ценят, и авторы благодаря им зарабатывают репутацию, поскольку они никогда не ссылаются на книги, из которых заимствуют... (англичане. - A. К.) - большие любители своего языка, и он прекрасно подчеркивает их изнеженность, поскольку освобождает их от необходимости двигать губами: при этом он очень богат и легко адаптируется, хотя и представляет собой искаженный тевтонский или немецкий, которые, несомненно, очень бедные языки; но все же он провозглашает своей целью обогатиться всем, чем только возможно, от всех мертвых языков, и каждодневно впитывать все достойное и лучшее от других живых» (Sorbière, Sprat, 1709: 70). За обычными в то время культурными предрассудками кроется признание будущего многообразия и совершенства английского языка. 
Сходна и его реакция на английский театр: «Актеры и актрисы играют прекрасно... Но во Франции на них бы не обратили почти никакого внимания, настолько далеко французы обогнали англичан на этом пути. Их поэты смеются над единством места и правилами времени: в их пьесах действия длятся и пять и десять лет; и после того, как в первом акте они показывают рождение принца, во втором появляется его сражающийся сын... Но лучше всего им удается показать человеческие страсти, добродетели и грехи... они говорят, что их интересует дишь то, как части (пьесы. - A. K.) следуют одна за другой, и не обращают внимание на композицию в целом» (там же: 69-70); «Их комедии написаны как будто белым стихом, который передает обычную речь лучше, чем наш метр (александрийский стих. A. K.), и довольно мелодичен: они не считают правильным раздражать ухо одним и тем же ритмом и говорят, что слушать героический стих в течение двух или трех часов подряд... неестественно...» (там же: 70-71).

Несоответствие английского театра нормам эпохи, формируемым французской школой неоклассицистов (иногда называемых еще французскими формалистами), не осталось незамеченным английскими современниками Сорбьера. У них было два пути решения этой проблемы: первый, более сложный и в конечном счете не реализованный, предполагал утверждение самобытности английской театральной и языковой традиции перед французским лицом эпохи; второй же - пытаться соответствовать указанным нормам путем адаптации старых текстов и написания новых в доминирующей эстетике - был воплощен на практике многими драматургами последней трети XVII - начала XVIII в., в их числе признанные мастера шекспировских адаптаций Уильям Аавенант (1606-1668) и Ажон Арайден (1631-1700).

Как уже упоминалось, с точки зрения зрителей и читателей второй половины XVII - начала XVIII в., Шекспир сильно уступал галантному идеалу эпохи: корпусу пьес Бомонта и Флетчера (по специфическим причинам доля новых, написанных после Реставрации пьес была крайне низка; подробнее см.: Taylor, 1990: 7-60). При этом общая оценка его творчества колебалась от уже процитированного раймеровского сравнения шекспировских пьес с грубым лаем мастифа до драйденовской ремарки из предисловия к адаптации «Троила и Крессиды» о том, что в части создания персонажей и возбуждения у зрителя приличествующих страстей Флетчер лишь подражал Шекспиру, и потому в данном случае глупо имитировать его, ведь таким образом мы «всего лишь подражаем имитатору» (Dryden, 1900: 220).

Общее число шекспировских адаптаций в указанную эпоху известно нам достаточно неплохо (см. подробней: The London stage, 1960-1968). Наиболее популярными среди них были:

1) «Гамлет» Аавенанта (1661), одна из первых успешных адаптаций драматурга;

2) «Макбет», поставленный Аавенантом в 1664 г. в виде оперы;

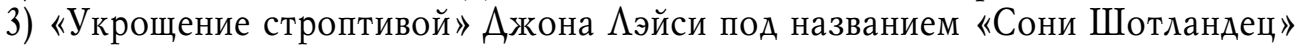
(Sauny the Scot); наибольшей популярностью пользовалась добавленная сцена, в которой есть попытка раздевания Катерины; первая постановка состоялась в 1667 г.;

4) Уже упоминавшаяся «Буря» Аавенанта и Арайдена, адаптация называлась «Буря, или Заколдованный остров» (The Tempest, or The Enchanted Island; 1667); 
5) «История короля $\Lambda$ ира (The History of King Lear) Наума Тэйта, в которой была целиком вычеркнута роль Шута, а в конце зрителей ждал счастливый брак между Эдгаром и Корделией; т. е. Тэйт превратил трагедию в трагикомедию; ее первая известная постановка состоялась в 1681 г. Эта версия пьесы преобладала в театрах до начала XIX в.;

6) «Троил и Крессида, или Правда, обнаруженная слишком поздно» (Troilus and Cressida, or Truth Found Too Late) Арайдена, опубликованная в 1679 г.

Как видно, перед нами только адаптации, основанные на «облегчении текста». Основной их целью было приближение происходящего в пьесах к известным событиям недавнего прошлого. Например, в адаптированной Ажоном Крауном «Буре» Калибан, Тринкуло и Стефано спорят друг с другом как члены парламента; «Генрих VI» напоминает об ужасах восстания против законного монарха, сюжет адаптации «Тита Андроника» пера Эдварда Равенкрофта оказывается связан с папистским заговором и т. п. В наиболее радикальных случаях адаптация оказывалась запрещена прежде, чем смогла быть хоть раз поставлена. Наиболее известный пример этого - адаптация «Ричарда II» (1681, название адаптации - «Сицилийский узурпатор» / The Sicilian Usurper) Н. Тейта, где была проведена очевидная для современников параллель между Карлом II и никого не слушающим, склонным к неге монархом из пьесы. Изменениям подвергался и сам текст пьес:

1) убиралось все непонятное и чрезмерное, - «провисающие» сцены с второстепенными персонажами и сами эти персонажи; сложные и устаревшие слова и речевые обороты и т. п.;

2) речь героев приводилась в соответствие с их социальным статусом;

3) текст пьес стандартизировался (в первую очередь это касалось написания слов), было возрождено пятиактное членение (в елизаветинском театре перерывы в тексте пьесы зависели от конкретного постановщика и конкретного представления; в перерывах между актами разыгрывались различные мини-представления: сценки, фарсы, фокусы и т. п., чтобы публика могла немного отвлечься);

4) стирание границы между театральным и оперным представлениями, ставшее возможным благодаря камерной атмосфере театра, введению обязательного музыкального аккомпанемента и музыкальных номеров в междуактовый промежуток, породило необходимость к изменению структуры фраз, - новые правила декламации требовали ритмичной речи, произносимой нараспев.

И если с последними двумя пунктами все понятно, то первые требуют иллюстрации.

Вот фрагмент известного монолога леди Макбет из «Макбета» в варианте, изданном в Первом фолио (I, 5):

Come to my Womans Brests,

And take my Milke for Gall, you murth'ring Ministers,

Where-euer, in your sightlesse substances,

You wait on Natures Mischiefe. Come thick Night, And pall thee in the dunnest smoake of Hell,

That my keene Knife see not the Wound it makes,

Nor Heauen peepe through the Blanket of the darke,

To cry, hold, hold.

(Shakespeare, 1623: 134) 
А вот этот же фрагмент в давенантовской адаптации (1664):

Come, and fill my Breasts

With Gall instead of Milk: make haste dark Night

And hide me in a smoke as black as Hell,

That my keen steel see not the wound it makes,

Nor heave'n peep through the curtains of the dark

To cry "Hold, hold!"

(Davenant, 1961: 90)

Из сравнения приведенных типических фрагментов видно, что Аавенант везде, где можно:

а) привел написание слов к современному: "Brests" на "Breasts", "Milke" на "Milk", "keene" на "keen" и т. п.;

б) упростил архаичный синтаксис Шекспира, убрал лирическое отступление “...you murth'ring Ministers, // Where-euer, in your sightlesse substances, // You wait on Natures Mischiefe" и смысловые повторы (например, "Come to my Womans Brests"), чтобы сделать речь короче и тем самым сильнее. Хотя совершенно не очевидно, что у него таким образом лучше получилось передать реальность гнева леди Макбет: некоторая путаность ее речи легко объясняется тем, что в гневе она, по замыслу Шекспира, заговаривается. Отказ от эмфатических повторов в пользу простоты выражения тоже выглядит чужеродным, несвойственным шекспировской эстетике. Но именно в таком варианте пьеса имела определенный успех, оригинал же оставался практически невостребованным;

в) так же симптоматична замена обыденно-вульгарных "dun", "knife" и "blanket" на более "героико-поэтические» "black", "steel” и "curtains" соответственно. Шекспировед Ф. Э. Холлидэй писал: «По сути, целью (подобных изменений. A. K.) было избавиться от той фарсовости / низкой комедии, до которой часто опускался Шекспир; непристойности, в отличие от вульгарностей, вполне проходили проверку и даже были желанны» (Halliday, 1960: 14).

Все пьесы Шекспира были переработаны в похожем духе. Важность проблемы языка четко осознавалась имитаторами елизаветинской драмы. Англичане именно в эпоху Реставрации, пожалуй, впервые столкнулись с необходимостью рефлексии своего лингвистического положения и нашли свое текущее состояние крайне неутешительным.

\section{ПРОБАЕМА ЯЗЫКА И ЕЕ ВОЗМОЖНЫЕ РЕШЕНИЯ В ПРЕАСТАВАЕНИИ ИОНАОНСКОГО КОРОАЕВСКОГО ОБЩЕСТВА И РАННЕЙ КРИТИКИ ЭПОХИ РЕСТАВРАЦИИ}

Сравнивая лингвистическую ситуацию в Античности и современной ему Англии применительно к драматургии, Арайден писал: «Во времена этого поэта (речь идет об Эсхиле. - A. К.) греческий язык достиг абсолютного совершенства; они (греки. - A. K.) пользовались строгой нормой разговорной и письменной речи; английский язык не способен на подобную точность, и мы лишь сейчас начинаем приближаться к нашей цели - идеальной грамматике. Тем не менее, необходимо отметить, что язык со времен Шекспира настолько рафинировался, что многие из его слов и фраз едва понятны. А те, что понятны, - частью нарушают правила 
грамматики, частью грубы и неуклюжи; и весь его стиль столь перенасыщен изобразительными средствами, что воспринимается как излишне эмоциональный и невнятный. Правда, в поздних пьесах ему до некоторой степени удалось улучшить стиль, но трагедия ( «Троил и Крессида». - A. K.), которую я взялся исправить, вероятнее всего, является одной из его первых постановок» (Dryden, 1900: 202-203).

Представление о родном языке как несовершенном и требующем улучшения, огранки разделялось многими английскими деятелями культуры той эпохи, и, очевидно, Шекспир был первым, к кому хотели бы применить такую огранку. При этом нельзя сказать, что, по мнению образованных зрителей эпохи Реставрации, он был плох во всем с точки зрения языка. Тот же Арайден признавался, что хотя он «часто осовременивал его язык, в определенных случаях (он. - A. К.), напротив, приближал свой язык» к шекспировскому (ibid: 203-204), благодаря чему пьеса теряла в изяществе, но приобретала в значительности. Анализируя «Отелло», непревзойденный в своей язвительности главный антагонист Шекспира в эпоху Реставрации Томас Раймер не раз давал критическую оценку пьесе в целом (наиболее известна его формула «кровавый фарс» (Rymer, 1956: 164)), но при этом даже у него нашлось несколько теплых слов о сцене возбуждения Яго ревности в Отелло, возвысившей пьесу «выше всех наших (т. е. современных Раймеру. A. K.) трагедий в наших театрах» (ibid: 147-148). Известный пиндарический поэт и критик начала XVIII в. Ажон Аеннис (1658-1734), отличавшийся от своих современников большей терпимостью к инаковым текстам, так и вообще объявил Шекспира «одним из величайших гениев трагедии, которых видел мир» (крайне нетипичная на тот момент точка зрения), и признавался, что «сделал чтение его одним из главных своих наслаждений и все не может насытиться» (Dennis, 1903: 46).

Но в целом успехи Шекспира, по мнению просвещенных критиков, достигались инстинктом, как суммировал драйденовское, а с ним и любое другое отношение к заданной проблеме, исследователь Уильям Фрост (Frost, 1969: 196).

Все сказанное возвращает нас к сочинению Сорбьера, впервые, насколько нам известно, остро поставившего проблему языка, а точнее - к ответу на него секретаря Аондонского королевского общества Томаса Спрата. Аержим в уме, что свой ответ Спрат писал до того, как драматурги эпохи Реставрации в лице У. Аавенанта, Аж. Арайдена, Т. Шэдуэлла, Т. Киллигрю и других прямо пошли по пути адаптаций существующего корпуса драматических текстов под новый вкус.

Реакция Спрата была быстрой и яростной. Разумеется, он нашел в очерке Сорбьера множество мелких недочетов и натяжек. Конечно, английский язык и английский театр были на самом деле лучше, чем описал француз. Более того, именно английская драма и должна занять место французской как более разнообразная. Его взгляды суммировал исследователь Ажордж Уильямсон: «Природа удовлетворена белым стихом. Спрат принимает понятие единств с уточнением, что они должны служить наслаждению, но отвергает французскую доктрину декорума и использование рифмы в интересах естественности. Английские пьесы превосходят (французские. - $A$. К.) одновременно и в следовании природе и искусству, английский способ закончить драму превосходит и потому, что он живее, и потому более поучителен в качестве примера» (Williamson, 1966: 68-70).

Но, в конечном счете, Спрат превозносил английский театр не за его самобытность, а за более естественное следование духу правил, которым нужно соответ- 
ствовать (поскольку признание верховенства французской театральной модели, т. е., в данном случае - единств, неизбежно означает необходимость защиты английского театрального наследия на основе принимаемой этой моделью аргументации). Французское замечание о незнании «трех единств» он с негодованием отвергает: говоря о несоблюдении правил английскими поэтами, Сорбьер допускает гораздо более серьезное несоответствие, «смешивая правление Карла II с елизаветинским. Верно, что около ста лет назад английские поэты не были так точны в этом отношении, но это в той же степени касается и драматургов других стран. C тех пор как другие стали смеяться над этими глупостями, стали их высмеивать и англичане, и вот уже пятьдесят лет как наш театр точен в этом отношении, как и в Европе »³ (Sorbière, Sprat, 1709: 166; далее он находит несоответствия единствам у французов. - A. K.).

Однако, несмотря на данную отповедь, соображения Сорбьера были восприняты очень серьезно. Практически сразу после публикации сочинения, а именно 7 декабря 1664 г., при Королевском обществе был создан специальный комитет с целью реформирования языка и словесности, вначале - в работе самого Общества, а затем и повсеместно. Среди его членов сразу выделились две неравные группы. Одна, меньшая, состоящая из признанных мастеров словесности, таких как Ажон Арайден, Абрахам Каули и Эдмунд Уоллер, хотела постепенного, естественного насыщения языка выразительными средствами путем его постоянного использования, т. е. больше практики в естественных условиях. Аругая, более радикальная, в основном состоящая из натурфилософов Общества, к которым примкнул и Спрат, бичевала метафоры и темные места и требовала математической точности: «...нет ничего проще, чем... использовать это злостное множество чеканных фраз, этот обман метафорами, эту бескостность языка, которые делают столько шума в мире... общество требует от всех своих членов естественности, открытости в речи... природной легкости и максимальной приближенности к математической точности» (Thomas Sprat's History ..., 1958: 111-113). И самое главное необходимо «предпочесть язык ремесленников, сельских жителей и торговцев измьилениям схоластов (там же: 113 ; курсив наш. - A. К.)» как более приближенный к известному идеалу.

Спрату вторит Раймер, в 1674 г. писавший, что английский язык «прекрасно подходит для выражения величия (т. е. для трагедий), именно потому, что во всех остальных различие между театральной и живой речью принуждает к использованию неподходящих размеров: французского александрийского стиха или италоиспанской героической стансы, в то время как английский же белый стих, являющийся, по сути, подражанием обычной речи, неразрывно связан с последней, что является его большим достоинством (Rymer, 1956: 3-4).

Особое внимание он уделяет процессу культивации языка. Огромное значение имеют коммерция и культурный обмен (ibid: 4) (в это время на континенте превозносили обогащение новых языков посредством изучения древних), и прав был Чocep (ibid: 126-127), обогативший английский язык такими методами; последнее утверждение можно было с полным правом отнести и к Шекспиру, но, к сожалению, Раймер на практике отказывает в серьезности тем авторам, которые увлекаются языком купцов. Его отношение к Шекспиру в этом - яркий пример: Раймер разделяет популярное в ту эпоху мнение, что «гений Шекспира лежит в комедии 
и юморе» (там же: 169), отвергая эти же шекспировские черты и приемы в его трагедиях и тем самым отрицая возможность того, что Шекспир может положительно влиять на английский язык.

Вероятно, именно в этом психологическом несоответствии и кроется причина, почему декларации о необходимости подражать живому языку третьего сословия так и остались декларациями: вкус әпохи был слишком французским, и старым пьесам недоставало изящества. В результате выиграла группа Аж. Арайдена, поддерживавшая идею постепенного обогащения языка. Но и их проект после смерти основных участников оказался не востребован.

\section{ЗАКАЮЧЕНИЕ}

Еще одним лингвистическим проектом, который необходимо упомянуть, был милтоновский проект Ажозефа Аддисона, активно, но безуспешно пропагандировавшего творчество поэта в своих эссе в «Наблюдателе» (The Spectator) в первые десятилетия XVIII в. Проект не вызвал особого интереса.

И лишь после этого и во многом благодаря деятельности зарождающейся буржуазии (женский «Шекспировский клуб», новое поколение молодых филологов из третьего сословия, таких как главный редактор изданий Шекспира Аьюис Тибальд и др.) английские интеллектуалы отошли от олицетворяемой Францией «континентальной» (аристократической) линии в лингвистической политике и вновь заинтересовались простым и живым языком елизаветинского театра, освободили Шекспира и других авторов от многочисленных текстуальных наслоений, образовавшихся в период повального адаптирования их текстов, тем самым позволив использовать обретенные тексты для создания общенационального английского литературного языка.

При этом нельзя сказать, что в своей деятельности они опирались на критический опыт предшествующего поколения. Спрат и Раймер оказались не услышаны, в результате чего на протяжении более чем 50 лет английская культура шла по другому пути, впоследствии признанному ошибочным. Однако было бы неверно считать, что ничто из созданного в то время не имеет значительной культурной ценности. Многие переделки шекспировских пьес, написанные именно в ту эпоху, спокойно дожили до начала XIX в. в репертуаре крупных английских театров (и были заменены постановками по оригиналу лишь на поднятой романтиками волне интереса к подлиннику) и до сих пор считаются эталоном сценической адаптации.

Подводя итог вышесказанному, можно заметить, что возникшая в эпоху Реставрации проблема улучшения языка не разрешилась (да и не могла быть решена) при помощи существовавших тогда интеллектуальных ресурсов. Из двух вариантов - отстаивание своей самобытности перед лицом более развитой французской культуры и подстройка под нее, в литературе и театре вылившаяся в адаптацию культурного наследия под новые реалии, - вначале неизбежно должен был быть выбран второй, как менее рискованный и трудоемкий. При этом английская культура уже была достаточно развитой, чтобы иметь проработанную альтернативную позицию, представленную Спратом и Раймером, в том числе и на примере шекспировских текстов отстаивавшим приоритет «живой» речи третьего сословия над литературными прожектами критиков. И в конечном счете именно эта пози- 
ция возобладала, позволив Шекспиру стать в центр лингвистического канона современного английского языка.

\section{ПРИМЕЧАНИЯ}

1 Речь идет о процессе трансформации высшего общества из родовой влиятельной / военной аристократии в аристократию «по духу», произошедшем в XVII в.: любой, чьи манеры были безупречны и вкус отменным, мог войти в высший свет как «равный». Основным толчком, побудившем к такой трансформации, явилась произошедшая под влиянием испанских и французских публицистов (например, труды Балтасара Грасиана:

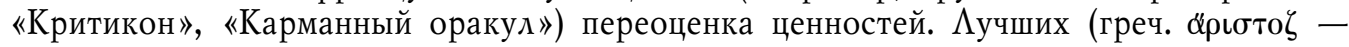
лучший) людей теперь определяет не родовитость, власть или богатство, а способность к мгновенному и чистому (незамутненному) восприятию красоты; их определяет «вкус». Наличие и острота вкуса лежат в основе внутренней иерархии (однако нередко монарх арбитр вкуса, т. е. положение определяет способность, в меньшей степени это свойственно и другим наиболее родовитым представителям знати). Гадамер трактует «вкус» (XVII в.) как изначально присущее некоторым людям требование избегать утрированности, несоразмерности, из чего следует, что первична дихотомия вкус (хороший) / отсутствие вкуса, а не хороший / плохой вкус (поскольку речь идет о естественности реакции). Необходимость градуировать вкус, в свою очередь происходящая из необходимости прививать его будущим поколениям, еще только начала осознаваться ведущими критиками (Гадамер, 1988: 50-85).

2 В английском литературоведении принята периодизация не по культурным, а по политическим эпохам, поэтому специалисты по рецепции Шекспира говорят не о барочном или классицистическом Шекспирах, а о Шекспире эпохи Реставрации или августианском Шекспире. Рамки самой Реставрации также четко не определены: в узком смысле речь идет о временном промежутке 1660-1688: о правлениях Карла II (1660-1685) и Якова II (1685-1688), а в широком - также он включает в себя периоды правления Марии и Вильгельма Оранских (1689-1702) и начало правления королевы Анны (1702-1714), так называемый августианский период. См., например, хронологическую таблицу, составленную Элоком Ядавом, доцентом кафедры английского языка колледжа гуманитарных и социальных наук Университета Ажорджа Мэйсона (Yadav: Электронный ресурс).

3 Это, очевидно, не так. Спрата отчасти извиняет то, что он не знал, когда написана шекспировская «Буря», в его время она считалась ранней пьесой Шекспира; да и в 1720-1740-е годы такие несоответствия единствам, конечно, встречались.

Если бы Спрат не просто пытался показать, что англичане не менее учены, чем французы, он бы сразу же обратил внимание на одну очевидность, а именно на то, что французский театр ориентировался на древних в первую очередь потому, что не имел длительной театральной традиции, в то время как для англичан «елизаветинцы» и были древними. И это отчасти подтверждается использованием современными Спрату драматургами белого стиха в новых пьесах и адаптациях, который он защищает, к сожалению, не как традицию и следование более успешным образцам, а как дань Природе.

\section{СПИСОК АИТЕРАТУРЫ}

Гадамер, Х.-Г. (1988) Истина и метод: основы философской герменевтики. М. : Прогресc. $704 \mathrm{c}$.

Davenant, W. (1961) Macbeth. From the Yale manuscript: An edition, with a discussion of the relation of Davenant's text to Shakespeare's / ed. by C. Spencer. New Haven : Yale University Press. ix, 226 p. 
Dennis, J. (1903) On the genius and writings of Shakespeare // Eighteenth century essays on Shakespeare / ed. by D. N. Smith. Glasgow : James MacLehose and Sons. 1xiii, 358 p. P. 25-46.

Dryden, J. (1900) Preface to Troilus and Cressida containing the grounds of criticism in tragedy // Dryden J. Essays : in 2 vols. / ed. by W. P. Ker. Oxford : Clarendon Press. Vol. 1. 414 p. P. 202-229.

Frost, W. (1969) Dryden's theory and practice of satire // Dryden's mind and art / ed. by B. King. Edinburgh : Oliver and Boyd. ix, 213 p. P. 189-205.

Halliday, F. E. (1960) The cult of Shakespeare. N. Y. : T. Yoseloff. xiii, 218 p.

Rymer, T. (1956) The critical works of Thomas Rymer / ed. by A. C. Zimansky. New Haven : Yale University Press. li, 299 p.

Shakespeare, W. (1623) Mr. William Shakespeares comedies, histories, \& tragedies. L. : Edward Blount; William Jaggard. 445 p.

Sorbière, S., Sprat, T. (1709) A voyage to England: containing many things relating to the state of learning, religion, and other curiosities of that kingdom by Mons. Sorbière. As also, Observations on the same voyage, by Dr. Thomas Sprat, Lord Bishop of Rochester. With a letter of Monsieur Sorbière's, concerning the war between England and Holland in 1652: to all which is prefix'd his life writ by M. Graverol. Done into English from the French original. L. : J. Woodward. xix, [1], 190 p.

Taylor, G. (1990) Reinventing Shakespeare: A cultural study from the Restoration to the present. L. : Hogarth Press. 461 p.

The London stage, 1660-1800 (1960-1968) : A calendar of plays, entertainments \& afterpieces, together with casts, box-receipts and contemporary comment. Compiled from the playbills, newspapers and theatrical diaries of the period : in 5 parts. Carbondale : Southern Illinois University Press.

Thomas Sprat's History of the Royal Society of London (1958) / ed. by J. I. Cope, H. Whitmore Jones. L. : Routledge and Kegan Paul. 448 p.

Williamson, G. (1966) The occasion of an essay of dramatic poesy // Essential articles for the study of John Dryden / ed. by H. T. Swedenborg. Hamden, CT : Archon Books. xv, 587 p. P. 65-82.

Yadav, A. Historical outline of Restoration and 18th-century British literature [Электронный ресурс] // George Mason University. URL: http://mason.gmu.edu/ ayadav/historical\%20outline/overview.htm [архивировано в WebCite] (дата обращения: 12.05.2016).

Aата поступления: 15.05.2016 2.

\section{DISCUSSIONS OF SHAKESPEARE'S LANGUAGE AND ITS IMITATIONS \\ IN LATE 17TH - EARLY 18TH CENTURY}

\section{A. I. KUZMICHEV}

(INSTITUTE OF SCIENTIFIC INFORMATION ON SOCIAL SCIENCES,

RUSSIAN ACADEMY OF SCIENCES, MOSCOW)

The second half of the 17 th century marked the time when the French formalist school of literary criticism was at the height of its domination in England. This school saw literature's primary goal in provision of models to be emulated by young aristocratic audience. Shakespeare, whose works had only just started to regain popularity after the years of oblivion during the Commonwealth. Shakespeare was now considered inappropriate for the role of the mentor of morals and manners due to the violence he depicted on stage and incoherence between the speeches of some of his heroes and their social position. The taste of the era was rather on the side of Francis Beaumont and John Fletcher in the matter of imitation. 
At this time the problem of improving and refining language first arose in the English culture. One of the catalysts for the rising debate on language might have been the travel book of Samuel Sorbiére (1664). English intellectuals came up with two possible solutions to the problem: protecting their cultural and linguistic uniqueness by proclaiming the priority of the language of the third estate - or adapting their cultural heritage to the new (French) fashions of the era. At first, the latter way was taken, which we prove by analyzing a number of 17 th-century adaptations of Shakespeare.

However, in the end the former solution prevailed, backed by the historiographer of the London Royal Society Thomas Sprat and the first English literary critic Thomas Rymer. To justify his position, Rymer cited the language of Shakespeare whom he complimented on his choice of language perfect in self-enriching by absorbing new linguistic models and strategies. At the time, their arguments were not universally accepted, and it was only in the second half of the 18th century that intellectuals of the later generations finally succeeded in establishing the priority of this model, thus placing Shakespeare in the center of the literary and linguistic canon.

Keywords: William Shakespeare; language of the works of Shakespeare; history of literature; English literature; 17th century; John Dryden; Thomas Rymer; Thomas Sprat; Samuel Sorbière

\section{REFERENCES}

Gadamer, H.-G. (1988) Istina i metod: osnovy filosofskoi germenevtiki. Moscow, Progress Publ. 704 p. (In Russ.).

Davenant, W. (1961) Macbeth. From the Yale manuscript: An edition, with a discussion of the relation of Davenant's text to Shakespeare's / ed. by C. Spencer. New Haven, Yale University Press. ix, $226 \mathrm{p}$.

Dennis, J. (1903) On the genius and writings of Shakespeare. In: Eigbteenth century essays on Shakespeare / ed. by D. N. Smith. Glasgow, James MacLehose and Sons. 1xiii, 358 p. Pp. 25-46.

Dryden, J. (1900) Preface to Troilus and Cressida containing the Grounds of Criticism in Tragedy. In: Dryden, J. Essays : in 2 vols. / ed. by W. P. Ker. Oxford, Clarendon Press. Vol. 1. 414 p. Pp. $202-229$.

Frost, W. (1969) Dryden's theory and practice of satire. In: Dryden's mind and art / ed. by B. King. Edinburgh, Oliver and Boyd. ix, 213 p. Pp. 189-205.

Halliday, F. E. (1960) The cult of Shakespeare. New York, T. Yoseloff. xiii, 218 p.

Rymer, T. (1956) The critical works of Thomas Rymer / ed. by A. C. Zimansky. New Haven, Yale University Press. li, $299 \mathrm{p}$.

Shakespeare, W. (1623) Mr. William Shakespeares comedies, bistories, \& tragedies. London, Edward Blount; William Jaggard. 445 p.

Sorbière, S. and Sprat, T. (1709) A voyage to England: containing many things relating to the state of learning, religion, and other curiosities of that kingdom by Mons. Sorbière. As also, Observations on the same voyage, by Dr. Thomas Sprat, Lord Bishop of Rochester. With a letter of Monsieur Sorbière's, concerning the war between England and Holland in 1652: to all which is prefix'd his life writ by M. Graverol. Done into English from the French original. London, J. Woodward. xix, [1], $190 \mathrm{p}$.

Taylor, G. (1990) Reinventing Shakespeare: A cultural study from the Restoration to the present. London, Hogarth Press. 461 p.

The London stage, 1660-1800 (1960-1968) : A calendar of plays, entertainments \& afterpieces, together with casts, box-receipts and contemporary comment. Compiled from the playbills, newspapers and theatrical diaries of the period : in 5 parts. Carbondale, Southern Illinois University Press. 
Thomas Sprat's History of the Royal Society of London (1958) / ed. by J. I. Cope and H. Whitmore Jones. London, Routledge and Kegan Paul. 448 p.

Williamson, G. (1966) The occasion of an essay of dramatic poesy. In: Essential articles for the study of Jobn Dryden / ed. by H. T. Swedenborg. Hamden, CT, Archon Books. xv, 587 p. Pp. 65-82.

Yadav, A. Historical outline of Restoration and 18th century British literature. George Mason University [online] Available at: http://mason.gmu.edu/ ayadav/historical\%20outline/overview.htm [archived in WebCite] (accessed 12.05.2016).

Submission date: 15.05 .2016$.

Кузьмичев Арсений Игоревич - младший научный сотрудник отдела литературоведения Института научной информации по общественным наукам Российской академии наук. Адрес: 117997, Россия, г. Москва, Нахимовский пр-т, д. 51/21. Тел.: +7 (499) 128-88-81. Эл. алpec: kusmicheff@yandex.ru

Kuzmichev Arseniy Igorevich, Junior Researcher, Department of Literary Studies, Institute of Scientific Information on Social Sciences (INION), Russian Academy of Sciences. Postal address: 51/21 Nakhimovskii Ave., 117997 Moscow, Russian Federation. Tel.: +7 (499) 128-88-81. E-mail: kusmicheff@yandex.ru 